\title{
Investigation into the computational techniques of power system modelling for a DC railway
}

\author{
A. Finlayson ${ }^{1}$, C. J. Goodman ${ }^{2}$ \& R. D. White ${ }^{1}$ \\ ${ }^{1}$ Atkins Rail, UK \\ ${ }^{2}$ University of Birmingham, $U K$
}

\begin{abstract}
The use of computer simulation techniques is now a fundamental part of the design process for electrified railways and at the feasibility stage clients will often request detailed calculations to be performed for the basic design. This will establish a level of confidence in both the project and basic design parameters that will justify the capital expenditure further on in the project life-cycle.

This paper will address how the total impedance of a railway network may be represented, where the impedances of the traction return circuit and traction power system are either combined together to form one impedance or studied independent of one another. The accuracy of the modelling in this manner, particularly how it affects the accuracy of rail voltage results shall be assessed. It will also examine how much impedance is typically in the rails and what proportion this needs to be before it has an unacceptable effect on the numerical results. To assess this, a range of proportions will be studied, for example $70 \%$ of the total impedance to be modelled in the conductor with $30 \%$ modelled in the rails, $60 \% / 40 \%$, etc. In this way, a proper scientific assessment of the combined or split calculation methods can be made via simplified case studies.

Keywords: DC railway, modelling, simulation, computational techniques, accuracy, numerical method, rail voltage, stray current.
\end{abstract}

\section{Introduction}

DC electrified railway systems across the world are growing, both in passenger and freight traffic, as an alternative solution to increasing road congestion. DC electrified railways account for approximately $50 \%$ of electrified railway lines throughout the world [1]. This growth may be in the form of new build railway 
systems or the upgrade of existing railway systems and is inclusive of metro, tramway, light rail and heavy rail systems. However this growth has to be managed to ensure that the proposals for an improved infrastructure are designed both safely and correctly and that the design delivers value for money. Computer simulation is the tool that many consultants and manufacturers, associated with the rail industry, are using to evaluate proposals and validate final designs prior to the launch of the project and any major capital expenditure. The use of computer simulation techniques is now a fundamental part of the design process for electrified railways and at the tender stage clients will often request detailed calculations to be performed for the basic design [2]. This will establish a level of confidence in both the project and basic design parameters that will justify the capital expenditure further on in the project life-cycle.

\subsection{DC railway modelling and simulation}

Modelling and simulation are the names we use for applying the laws of physics and logic via the processing power of computers to predict the behaviour and performance of railway infrastructure [2]. The various levels of engineering modelling and simulation with respect to the DC railway may be considered as; timetable and operational planning, train performance and signalling, traction equipment and the power supply system. These engineering levels are not considered to be exhaustive but what is important is the power system supply, as this paper is primarily concerned with the modelling of the power system for the DC railway.

\section{The DC railway}

\subsection{Operational functions}

The DC railway usually has the primary operational function of passenger transportation, whereas the $\mathrm{AC}$ railway has the dual operational functions of passenger and freight transportation. However the DC railway may also be used within the mining industry, as well as freight transportation [3], so it may be considered to have dual operational functions also. However, for the purpose of this paper the DC railway shall be considered as predominantly suburban railways often referred to as transit systems. Transit systems may be classified based upon the demand for traction current from the power system. For example, a metropolitan railway (metro) may be considered to be a mass transit system as there will be more trains carrying more passengers with short headways between trains and therefore a large demand for traction current from the power system. Conversely, a tram railway may be considered to be a light rapid transit (LRT) system as there will be less trams and also less demand for traction current from the power system than the mass transit system.

Either of these systems may utilise an overhead line or third/fourth rail feeding arrangement. The following DC traction supplies are commonly used [4]: 
- $\quad 3000 \mathrm{~V}$ (overhead line)

- $1500 \mathrm{~V}$ (overhead line)

- $750 \mathrm{~V}$ (third rail and overhead line)

- $630 \mathrm{~V}$ (third and fourth rail)

\subsection{Components of the DC railway}

The DC electrified railway comprises of many interacting variables or components. These variables are usually contained within sub-systems such as; civil engineering, permanent way, electrification, signalling, tele-communications, rolling stock, station services and third parties outside the railway environment. Whilst this list is typical (non-exhaustive), all of these variables must be considered both individually and interacting with one another during the design process of a railway system. However, for the purpose of this paper the components that are of most concern are;

- Electrification

- $\quad$ Rolling stock

- $\quad$ Signalling

\subsection{Other considerations for modelling}

In studying the DC railway power system, there are two further technical problems that need to be included in the circuit model of the DC power system. Firstly, there is the variation of rail voltage with respect to the train operational timetable and secondly there is the magnitude of stray current with respect to the train operational timetable.

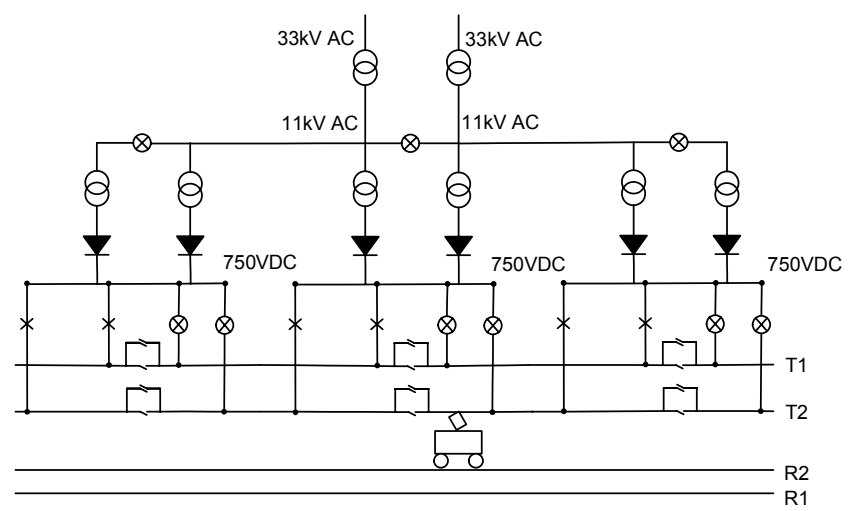

Figure 1: $\quad$ The DC railway represented in a single line diagram.

\subsection{DC railway operation}

Figure 1 shows a typical two track DC railway with one feeder station with a primary voltage of $33 \mathrm{kV} \mathrm{AC}$ and a secondary voltage of $11 \mathrm{kV} \mathrm{AC}$. The 
$11 \mathrm{kV} \mathrm{AC}$ is then rectified and an output voltage of $750 \mathrm{~V} \mathrm{DC}$ is produced which in turn will power the rolling stock on the rail network. The rolling stock will draw traction current from $\mathrm{T} 2$ and will return traction current through R2. However not all of the traction return current will return through the running rails and this may be due to the earthing and track bonding arrangements associated with the DC railway.

\section{Choosing the model and method}

\subsection{The basic model}

There are many methods available to us in solving the power system model of a DC railway. Examples of these may include multi-conductor modelling, finite element analysis or transmission line theory to name but a few. However, given the nature of the DC railway, the power system model may be considered to be dynamic, i.e. the electrical load changes with demand and with multiple electrical loads, i.e. trains. Whilst these parameters may appear complex, the DC railway power system is easier to model than the alternative AC railway. This is because the effects of capacitive and inductive reactance in the equivalent steady state circuits may be ignored due to the general principles of DC circuit theory [5]. Applying this to figure 1 will give rise to the equivalent circuit shown in figure 2 , where $Z_{\mathrm{c} 1}, Z_{\mathrm{c} 2}$ and $Z_{\mathrm{c} 3}$ represent the impedance of the traction power conductor, whilst $Z_{\mathrm{r} 1}, Z_{\mathrm{r} 2}$ and $Z_{\mathrm{r} 3}$ represent the impedance of the traction return conductor.

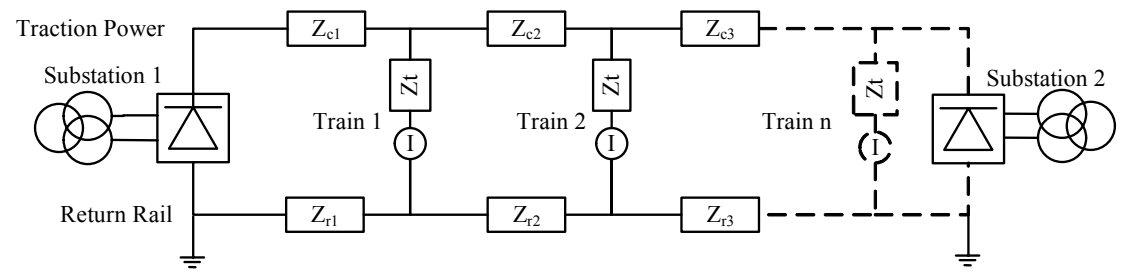

Figure 2: Electrical circuit for DC railway.

Figure 2 may still not be considered to be the simplest model of the DC railway. The electrical substations may be modelled in their Thévinin equivalent model, a voltage source $\left(\mathrm{V}_{\mathrm{s}}\right)$ with a source impedance $\left(\mathrm{Z}_{\mathrm{s}}\right)$ and the train may be modelled as an impedance $\left(Z_{t}\right)$ that is dependent upon whether the train is motoring, coasting or braking.

Figure 3 now shows two cases of the simplified circuit, with the Thévénin equivalent voltage source representing two electrical substations and a single train represented by an impedance somewhere between the two electrical substations. The circuit shown to the left of figure 3 represents the DC railway where the traction power and traction return conductors are split from one 
another, whilst the circuit to the right shows them combined. The circuit to the right suggests that the DC railway power system model may be solved as a simple DC circuit, using short transmission line theory [6].
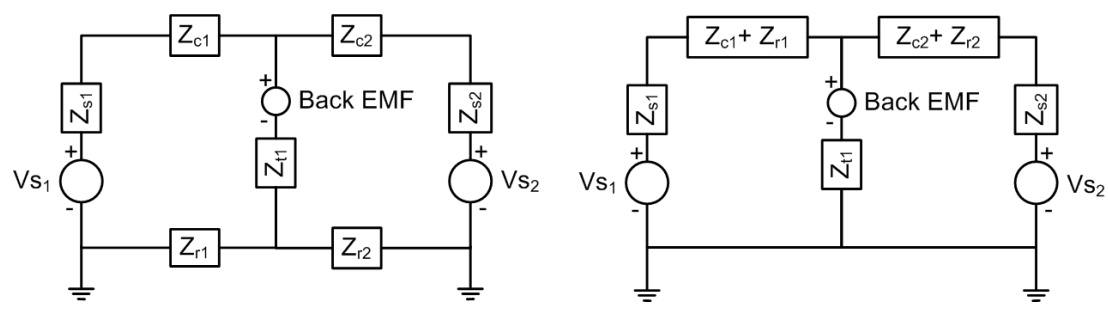

Figure 3: $\quad$ Simplified electrical circuit of a DC railway.
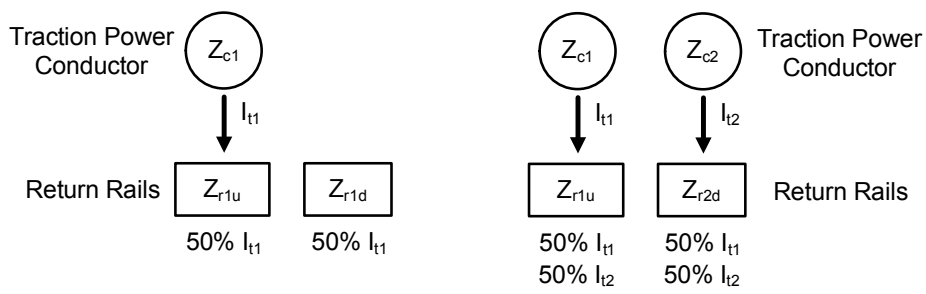

Figure 4: Developing the combined impedance model.

\subsection{Representing the traction return conductor in the combined impedance model}

Figure 3 is representative of a one track railway. In practice, the DC railway, under consideration for this paper, will usually be a minimum of two tracks, namely up (u) and down (d). Considering figure 4, there are two trains present, one on each track and there are four traction return conductors, or as is more commonly known return paths. These return paths are considered to have identical impedance characteristics and the percentage of traction return current $\left(\mathrm{It}_{1}\right.$ and $\left.\mathrm{It}_{2}\right)$ in each return path is shown.

Considering the configuration shown to the left of figure 4, will give rise to the equivalent impedance of all the return paths combined being expressed as:

$$
Z r_{n}=\frac{Z r_{1 u}}{n} \quad \Omega
$$

where ' $n$ ' is equal to the total number of traction return conductors in the circuit. However, considering the configuration to the right of figure 4 , the equivalent impedance of all the return paths combined will be expressed as:

$$
Z r_{n}=\frac{T^{*} Z r_{1 u}}{n} \Omega
$$


where $\mathrm{T}$ is the number of trains present. However, because the number of trains present between electrical substations and on different tracks varies, this will be difficult to program in a computer simulation tool. The equivalent impedance of all the return paths combined may be expressed as an alternative to equation 1 by

$$
Z r_{n}=Z r_{1 u} \Omega
$$

This paper will assess which the accuracy of modelling the equivalent return rail impedance as either equations 1 or 3 for a number of tracks, as these are feasible methods that may be used by computer simulation tools.

\subsection{The method}

Figure 3 may be solved via a number of well known network analysis techniques such as mesh or nodal analysis [5]. For simple circuits such as that shown in figure 3 where there is only 1 train present, the solution may be solved by deriving linear equations and solving them as simultaneous equations. If the circuit contains more electrical loads, it is better to solve the circuit via a series of linear equations represented in matrices where the general equation may be given as

$$
[V]=[Z] *[I]
$$

The computational efficiency of the numerical procedures undertaken by both mesh and nodal analysis may be measured by counting the number of numerical operations (OC) i.e. multiplication, division, addition and subtraction for each equation ' $\mathrm{N}$ ' to be solved, i.e. ' $\mathrm{N}$ ' is equal to the number of nodes in the circuit or the number of loop currents in the circuit, dependent upon the network analysis technique chosen. This may be defined as [10];

$$
O C=\frac{2 N^{3}}{3}+\frac{3 N^{2}}{2}-\frac{7 N}{6}
$$

Table 1 shows the difference in operational counts taking into account the simplified models shown in figure 3 . Table 1 illustrates that nodal analysis has a much lower OC when 4 or more linear equations are required to be solved. This can be attributed to the fact that in nodal analysis, each node represents an equation and one node has to be set to zero.

\section{Table 1: $\quad$ Summary of OC.}

\begin{tabular}{|c|c|c|c|c|}
\hline Number of Traction Return Paths & \multicolumn{2}{|c|}{ Mesh Analysis } & \multicolumn{2}{c|}{ Nodal Analysis } \\
\hline & $\mathrm{N}$ & OC & N & OC \\
\hline 1 & 2 & 9 & 2 & 9 \\
\hline 2 & 4 & 62 & 3 & 28 \\
\hline 4 & 8 & 428 & 5 & 115 \\
\hline 6 & 12 & 1354 & 7 & 294 \\
\hline 8 & 16 & 3096 & 9 & 527 \\
\hline
\end{tabular}


If using mesh analysis, each loop current represents an equation and each and every loop current must be used. This means that for an equivalent circuit that requires 4 or more equations to be solved, mesh analysis will always have one more equation to be solved than nodal analysis, thus meaning that nodal analysis is the more efficient method.

\subsection{Injecting train currents}

If the combined impedance circuit of figure 3 is used to solve the power system then it presents us with a problem as the technical issues cited in section 2.3 are not represented in the model, whereas the rail voltage is represented and calculated directly in the split impedance model. This problem may be overcome by either including these parameters in the model for real time simulation or they can be accounted for in a post processing program, i.e. a separate program that operates on the results from the initial simulation [7]. This may be done by injecting the train currents $\left(\mathrm{I}_{t}\right)$ into a homogenous rail. The ground impedance $\left(\mathrm{Z}_{\mathrm{e}}\right)$ is represented as a lumped parameter that ignores the effect of ground capacitance, because any reactive component represented by the ground will be so small that it can be ignored $[4,8$, and 9] and in any case is only relevant for transient conditions, as is shown in figure 5. The current flowing in the earth $\left(\mathrm{I}_{\mathrm{e}}\right)$ represents the stray current and this may also be studied as part of the post processing program.

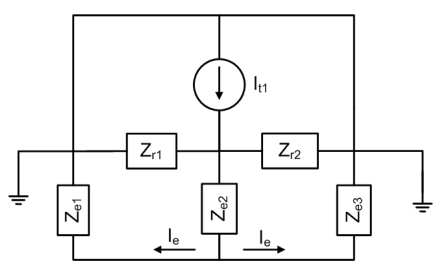

Figure 5: $\quad$ Post process injecting train currents model.

\section{Case studies}

The theoretical analysis of railway modelling techniques discussed in section 3 may be applied to the practical railway, where numerical analysis can be applied to ascertain the accuracy of modelling between the split impedance method (with the traction return path impedance modelled as per equation 2) and the combined impedance method with the equivalent traction return path impedance modelled as per equations 1 and 3 . The network analysis technique chosen was nodal analysis as this calculates the train voltage directly and is considered to be more efficient than mesh analysis, as defined in section 3.4. The following railway types have been identified as case studies;

- $\quad 1500$ V DC Overhead Line Railway (OHL)

- 750 V DC $3^{\text {rd }}$ Rail Conductor Railway

- 750 V DC Overhead Line Railway 
Practical traction return circuits, traction power system and voltage source impedances have been used in the case studies. A range of proportions have been studied, for example $60 \%$ of the total impedance to be modelled in the traction conductor $(\alpha)$ with $40 \%$ modelled in the rails etc., where the summation of the traction powers system and return circuit impedances is equivalent to the loop impedance $Z_{L}$. Each case study includes six traction return circuit with up to six trains present, i.e. one on each track.

\subsection{Calculating the error}

The train voltage may be expressed as a percentage of the supply voltage derived by the electrical substation. This may be expressed generally as;

$$
V t=\frac{V_{\text {train }}}{V s_{1}} \times 100 \quad \%
$$

where $\mathrm{V}_{\text {train }}$ is the train voltage and $\mathrm{Vs}_{1}$ is the electrical substation voltage. Equation 6 will satisfy both the split and combined impedance analyses. The error in train voltage calculation may be expressed as;

$$
\% \text { error }=V t_{\text {split }}-V t_{\text {combined }} \quad \%
$$

where $\mathrm{Vt}_{\text {split }}$ is the result of equation 6 for the split impedance model and $\mathrm{Vt}_{\text {combined }}$ is the result for the combined impedance method. A back calculation may be performed using the result of equation 7 to calculate the error in terms of voltage magnitude if required, as shown in equation 8 .

$$
V=\frac{\% \text { error }}{100} \times V s_{1} \quad V
$$

\subsection{Summary of results}

Table 2 shows the percentage error (\%) in train voltage calculation, using equation 7 .

\section{Discussion and conclusion}

\subsection{Discussion}

The results in table 2 suggest that either equations 1 and 3 for the equivalent traction return path impedance are satisfied when there is only one train present, as in the case of equation 1 and six trains being present, as in the case of equation 3. This does not definitively define which equivalent rail return impedance should be used. Therefore an intermediate step was introduced by assessing three trains being present. The choice for three trains is purely 


\begin{tabular}{|c|c|c|c|c|c|c|}
\hline \multirow{2}{*}{ 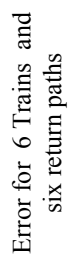 } & 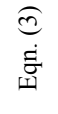 & $\begin{array}{l}\text { 苛 } \\
\text { o. } \\
\text { o. }\end{array}$ & 0 & 0 & 0 & 0 \\
\hline & $\begin{array}{l}\hat{\Xi} \\
\dot{\Xi} \\
\text { ज्ञ }\end{array}$ & $\begin{array}{l}\overrightarrow{0} \\
\dot{0} \\
0^{\circ}\end{array}$ & 萬 & 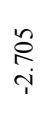 & $\begin{array}{l}\stackrel{\infty}{\circ} \\
\stackrel{0}{7}\end{array}$ & $\underset{\nearrow}{\stackrel{7}{7}}$ \\
\hline \multirow{2}{*}{ 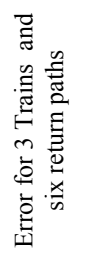 } & $\begin{array}{l}\text { (ิ) } \\
\text { घ्ञ }\end{array}$ & 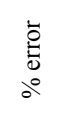 & Бे & స్ర్ర & 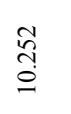 & $\begin{array}{l}\tilde{\stackrel{0}{0}} \\
\stackrel{\leftrightarrow}{0}\end{array}$ \\
\hline & $\begin{array}{l}\text { E } \\
\text { 竎 }\end{array}$ & 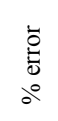 & $\begin{array}{l}\text { o. } \\
\text { in }\end{array}$ & 㣽 & \begin{tabular}{l}
\multicolumn{1}{c}{} \\
$\infty$ \\
$\vdots$ \\
$\vdots$ \\
$i$
\end{tabular} & 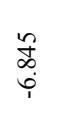 \\
\hline \multirow{2}{*}{ 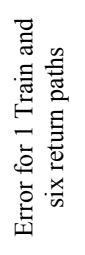 } & $\begin{array}{l}\text { (્) } \\
\text { E्ञ }\end{array}$ & $\begin{array}{c}\overrightarrow{0} \\
\frac{0}{0} \\
0^{\circ}\end{array}$ & : & $\stackrel{\substack{c \\
i}}{c}$ & $\begin{array}{l}\stackrel{\circ}{\circ} \\
\stackrel{\leftrightarrow}{=}\end{array}$ & $\stackrel{\cong}{\Xi}$ \\
\hline & $\begin{array}{l}\Xi \\
\dot{\Xi} \\
\text { ज्ञ }\end{array}$ & 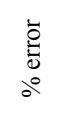 & 0 & 0 & 0 & 0 \\
\hline \multicolumn{3}{|c|}{ 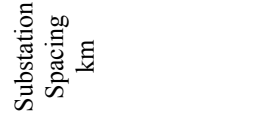 } & $\sim$ & $\because$ & $m$ & $n$ \\
\hline \multicolumn{3}{|c|}{ 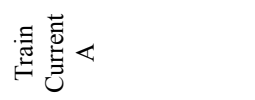 } & ঃे & $\underset{-}{8}$ & 嵩 & 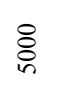 \\
\hline \multicolumn{3}{|l|}{ ஓे } & 8 & in & $\hat{m}$ & in \\
\hline \multicolumn{3}{|l|}{$\vec{N}$} & $\begin{array}{l}\text { 京 } \\
\vdots \\
0 \\
0\end{array}$ & 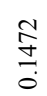 & $\begin{array}{l}\overrightarrow{\tilde{o}} \\
\stackrel{0}{0}\end{array}$ & $\begin{array}{l}\infty \\
\stackrel{0}{0} \\
\stackrel{0}{0} \\
0\end{array}$ \\
\hline \multicolumn{3}{|l|}{ 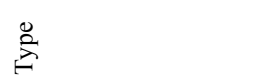 } & 志 & 吉 & 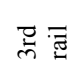 & 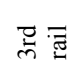 \\
\hline \multicolumn{3}{|c|}{ 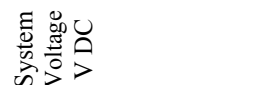 } & $\stackrel{8}{\circ}$ & in & in & in \\
\hline
\end{tabular}


academic and is used to define a utilisation factor of the traction return circuits, although in reality the number of trains may vary. This now shows that the error is lower when using equation 1 to derive the equivalent traction return impedance. However, whilst the error is acceptable for the overhead line railways, it is not so for the $3^{\text {rd }}$ rail railway. The impedance is too low in the traction power conductor, allowing a large voltage drop to occur between the train and the electrical substation, mainly due to the high values of current drawn by the trains. Furthermore, the impedance in the traction return circuit is more dominant and the inconsistency in the assumptions of equations 1 and 3 suggest that this impedance must be modelled accurately, i.e. as per equation 2 and the split impedance method.

Therefore this type of railway should be modelled as a split impedance railway, such that the train and rail voltages are calculated correctly. Furthermore, it is noticeable that the magnitude of percentage error increases as the number of tracks occupied increases. This must also be considered when deriving the power system model, with respect to split or combined impedance method.

\subsection{Conclusion}

The case studies confirm that the most efficient method for solving the power system model is to combine the traction power and return conductor impedances such that the OC of the circuit is reduced to as low as reasonably possible. This will allow post process simulation of the data obtained from the real time solution and allow effective management of the computing overhead that is always the fundamental driver with computational techniques and the desired accuracy. This statement is true, with the exception of the $3^{\text {rd }}$ rail traction conductor railway, where the most appropriate method would be to model the impedances of the railway separately.

\section{Acknowledgement and disclaimer}

Information and guidance given in this paper are views held by the authors. The authors would like to thank colleagues within Atkins Rail and the University of Birmingham for their support and advice in writing this paper and for their kind permission in allowing this work to be published as part of the collaborative agreement to develop a DC multi train simulator.

The authors, Atkins Rail and the University of Birmingham accept no liability to anyone for any loss or damage caused by any error or omission in the work, whether such error or omission is the result of negligence or any other cause.

\section{References}

[1] Profillidis, VA. (2000). Railway Engineering. $2^{\text {nd }}$ Edition. Aldershot: Ashgate Publishing Ltd. Chapter 13 pp252. ISBN 0 - $7546-1279-1$. 
[2] Goodman, CJ, (2005). Modelling and Simulation. The IEE Second Residential Course on REIS 2005. Wrightsons. Chapter D3. ISBN $0-$ $86341-511-3$.

[3] BS EN50122-1:1998 Railway applications - Fixed installations Part 1: Protective provisions relating to electrical safety and earthing.

[4] Kiessling, F, Puschmann, R, Scmeider, A. (2001). Contact Lines for Electric Railways. $1^{\text {st }}$ Edition. Munich Erlangen: Publicis Coproate Publishing Ltd. Chapter 1 pp33.ISBN 3 - 89578 - $152-5$.

[5] Bird, J. (2004). Electrical Circuit Theory and Technology. Revised $2^{\text {nd }}$ Edition. Newnes. Chapters 30, 31, 33, 44 pp 531 - 559, 575 - 598 and $869-900$. ISBN $0-7506-5784-7$

[6] Stevenson, WD Jr. (1982). Elements of Power System Analysis. ${ }^{\text {th }}$ Edition. McGraw Hill. Chapters 5, pp $88-126$. ISBN $0-07-066584-$ 2

[7] Yu, JG, (1992). Computer Analysis of Touch Voltages and Stray Currents for DC Railways. PhD Thesis submitted to the University of Birmingham, UK

[8] White, RD, Zhang, Z (2003) Atkins Rail internal report. Predictions of $50 \mathrm{~Hz}$ induced voltage into lineside cables on $25 \mathrm{kV}$ railway. Report Number: BF 5001270/RDW/001. Issue 4.0 August 2003

[9] Case, S, (2005). Earthing, Bonding and Stray Current Mitigation Principles. The IEE Second Residential Course on REIS 2005. Wrightsons. Chapter D4. ISBN $0-86341-511-3$.

[10] Gerald CF, Wheatley PO. (2004). Applied Numerical Analysis. $7^{\text {th }}$ Edition. Pearson/Addison Wesley. Chapter 2 pp 88 - 100. ISBN 0 - $321-1909-$ $\mathrm{X}$ 